\title{
ATTENTION, PERCEPTION AND THOUGHT IN ARISTOTLE
}

\author{
Phil Corkum, University of Alberta
}

ABSTRACT: In the first part of the paper, I'll rehearse an argument that perceiving that we see and hear isn't a special case of perception in Aristotle but is rather a necessary condition for any perception whatsoever: the turning of one's attention to the affection of the sense organs. In the second part of the paper, I'll consider the thesis that the activity of the active intellect is analogous to perceiving that we see and hear.

RESUMÉ: Dans la première partie de l'essai, je soutiendrai que percevant que nous voyons et entendons n'est pas un cas spécial de perception en Aristote mais suis plutôt une condition nécessaire pour n'importe quelle perception quelconques: l'attention à l'affection des organes sensoriels. Dans la deuxième partie de l'essai, je considérerai la thèse que l'activité de l'intellect actif est analogue à la perception cette nous voient et entendent.

Aristotle holds that there is a passive intellect, by which the mind can become any intelligible object, and an active intellect, by which the mind can make any intelligible object. What is the activity of the active intellect? In this paper, I'll argue that the role of the active intellect in thought is analogous to the role of perceiving that we see and hear in perception. Aristotle sometimes himself draws analogies between perceiving and thinking. One analogy, for example, concerns the relation holding between faculties and their objects. If thinking is like perceiving, then as the faculty of perception is to the object perceived, so too the faculty of thought is to the intelligible object. This analogy, suggested by De An. 3.4 (429a13-18), lends support to Aristotle's assimilation model of thought: in thinking, the faculty of thought becomes formally identical with the intelligible object. This model of thought is plausible in part since, by the time Aristotle makes the claim, he has already argued that, in perceiving, the faculty of perception 
becomes formally identical with the perceived object. Of course, there are also disanalogies between perception and thought. For example, where perception requires external stimulation of a sense organ by sensible substances, thought does not generally require external stimulation of an organ. Another disanalogy drawn between perception and thought at $429 \mathrm{a} 13 \mathrm{ff}$. is that there is the possibility of error in thinking but not in the perception of special objects - objects of just one sense, such as colours and sounds. How far then can we push the analogy?

The paper comes in two parts. In the first part, I'll rehearse an argument with the conclusion that perceiving that we see and hear isn't a special case of perception but is rather a necessary condition for any perception whatsoever. In particular, perceiving that we see and hear is a turning of one's attention to the affection of the sense organs. This conclusion was vigorously argued for by Aryeh Kosman in 1969 and versions of it have become something of the standard view, advocated for example by Osbourne and Caston. ${ }^{1}$ The argument I give differs in some ways from Kosman's argument, however, and I don't claim that any of these authors would agree with the details of my presentation. But it's worth returning to the issue of the role of perceiving that we see and hear in Aristotle's account of perception- this time, with an emphasis on those features which are arguably analogous with Aristotle's account of intellection.

In the second part of the paper, I'll consider the thesis that the activity of the active intellect is analogous to perceiving that we see and hear. If this is correct, then the activity of the active intellect is not a special case of intellection but rather a necessary condition of any intellection whatsoever. In particular, the activity of the active intellect is a turning of one's attention to the intelligible objects contained in the passive intellect. 
This also takes up a suggestion from Kosman—although the view in its broad strokes has a lengthy history as a minority opinion and has been endorsed, for example, by Brentano. Again, I don't claim that any of these authors would endorse every detail of my presentation. But, in recent times, Kosman's suggestion hasn't received the attention I believe it deserves. I'll assess the claim that the activity of the active intellect is a kind of attention and I'll address some interpretative difficulties for the claim. Finally, any interpretation of the active intellect will be judged in part by the light it sheds on other related topics in Aristotle's epistemology and philosophy of mind. It is a selling point for an attentive interpretation of the active intellect that it suggests interesting and not implausible interpretations of induction, Aristotle's account of concept acquisition, intuition, Aristotle's account of our grasp of first principles, and the divine intellect. I'll conclude the paper by broaching these issues.

\section{I}

In De An. 3.2 (425b12-25), Aristotle considers what we might call higher-order perception—perceiving that we perceive.

(a) Inasmuch as we perceive that we see and hear, it must either be by sight or by some other sense that the percipient perceives that he sees.

(b.1) But, it may be urged, the same sense which perceives sight will also perceive the colour which is the object of sight. So that either there will be two senses to perceive the same thing or the one sense, sight, will perceive itself. (b.2) 
Further, if the sense perceiving sight were really a distinct sense, either the series would go on to infinity or some one of the series of senses would perceive itself. Therefore it will be better to admit this of the first in the series.

(c) Here, however, there is a difficulty. Assuming that to perceive by sight is to see and that it is colour or that which possesses colour which is seen, it may be argued that, if you are to see that which sees, that which in the first instance sees, the primary visual organ, will actually have colour.

(d.1) Clearly, then, to perceive by sight does not always mean one and the same thing. For, even when we do not see, it is nevertheless by sight that we discern both darkness and light, though not in the same manner. (d.2) Further, that which sees is in a manner coloured. For the sense-organ is in every case receptive of the sensible object without its matter. And this is why the sensations and images remain in the sense-organs even when the sensible objects are withdrawn. ${ }^{2}$

Here's an outline of this passage. In (a), Aristotle raises a question for an account of perceiving that we see: is this higher-order perception the office of sight or another faculty? In (b.1) and (b.2), he gives two arguments against the latter claim. In (c), he raises a problem for the former claim; and in (d.1) and (d.2), he offers two solutions to this problem. The conclusion, I take it, is that perceiving that we see is the office of sight. $^{3}$

There are several difficulties in interpreting this passage. I'll begin by focusing on one of the two arguments given against the claim that the perception that we see is the office of a faculty distinct from sight. The argument of (b.1) rests on the assumption that 
whatever faculty perceives a special sense must also perceive the object of that sense: in the case of sight, colour. This grounds an argument against there being a separate sense for second-order perceptions. Aristotle doesn't make this argument explicit but perhaps he is thinking that the assumption violates the thesis, advanced in De An. 3.1, that for any type of sense object — such as colour — there's at most one sense. At first blush, this argument isn't persuasive. For there seems to be no reason to hold the assumption on which it rests. Consider an imaginative case offered by Kosman so to illustrate a somewhat different point. Suppose that our bodies were so wired that whenever we see, we emitted a low humming sound. Then we could hear that we see without of course hearing colours. A faculty of higher order perception could operate analogouslyalthough not, of course, by means of one of the special senses such as hearing. That is, even if we concede that the cognitive activity in question is a kind of perception, there is still no reason to think it is the office of the same perceptual faculty as the faculty whose activity is being perceived.

The argument of (b.2) seems just as weak. The danger of an infinite regress depends upon the assumption that in order for a distinct sense to perceive any perception of order $n$ by means of an $(n+1)$-order perception, there must be a further sense to perceive the $(n+1)$-order perception by means of an $(n+2)$-order perception. So for a distinct sense to perceive a special sense such as sight, there must be a further sense to perceive the second-order perception with a third-order perception, and so on. But this assumption seems clearly false. Why could a distinct sense not perceive a special sense such as sight without there being the further need for a perception of this second-order perception? 
So there are these two difficulties of interpreting our passage. But there are difficulties with each stage of the argument. Consider section (a). What cognitive activity is being described as perceiving that one sees or hears? And why is this form of cognition called perception? Unlike the other modes of perception, the object of such cognition is not a sensible object, an aistheton, but an activity, an aisthanesthai. This raises a problem for the following reason. The objects of perception are not generally truth bearers. Truth and falsity for Aristotle imply the combination and separation of what Aristotle, conflating propositional constituents and their expressions in language, calls names and verbs. In De Interpretatione 1 (16a13-15), Aristotle gives the example of a sensible quality, expressed by "white", which is neither true nor false. Aristotle sometimes speaks more loosely of perceptions being true. For example, at De An. 3.3, Aristotle claims that perceptions of the special senses (ton idion) are true or least subject to error. However, the sense in which perceptions are true is not that they imply combination and separation but that one cannot be in error that he is, say, seeing red. But the expression, "perceive that (hoti) I see and hear," used at 425b12, suggests that the objects of such perception are truth bearers: they are the combination of a name and a verb. If cognitions of sensible objects are non-veridical but cognitions of acts of perceiving are veridical, then the grouping together of both kinds of cognition under the label, "perception," seems strained.

The arguments in support of the claim that we perceive that we see by means of sight are no more lucid. The stated problem is that, since the object of sight is colour, if we perceive that we see by means of sight, then what we perceive in this higher-order perception, the sense organ, will be coloured. However, the problem rests on the 
seemingly false assumption that we can perceive that we see only if we perceive that which sees, the sense organ. Let us for the moment accept this assumption. I would speculate that the difficulty, which Aristotle is briefly canvassing here, is that the colour of the eye doesn't appear to be dependent on the colour of what is seen: pace Crystal Gayle, nothing seems to turn your brown eyes blue. If the assumption that we can perceive that we see only if we perceive the sense organ is true, then this apparent indifference of the external appearance cornea to the sense object is indeed problematic. But still, why accept the assumption?

What counterarguments does Aristotle offer? The response of (d.1) is that perception by sight is not one thing. The difficulty with interpreting this argument is to understand its relevance to the problem of (c). Hamlyn also questions the relevance of this move, writing that "perception by sight might be multifarious, as he indicates by the case of judging darkness and light, but not necessarily in the right respect." ${ }^{, 4}$ That it is by sight that we perceive darkness and light may show that perception by sight is not one thing. But it is fallacious to infer from this that it is by sight that we perceive that we see. At best, (d.1) opens the possibility of giving an argument for this conclusion. Perhaps this is Aristotle's intention, for section (d.2) gives just this argument. Despite appearances, the colour of the sense organ is in a manner dependent on the colour of what is seen. I will not enter into the well-worn controversy regarding in what manner the sense organ takes on the colour of the sense object-i.e., whether there is a physiological change in the organ. Of course, the sense organ proper is not the eye but the jelly inside the eye. So the fact that the cornea doesn't change colour with what is seen does not refute the claim. This explanation of these arguments makes some sense of (c)-(d), but only under the 
seemingly false assumption that we can perceive that we see only if we perceive that which sees, the sense organ. So we have yet to clarify any section of the passage.

These difficulties of reading the passage arise from a mistaken interpretation of Aristotle's view of perceiving that we see and hear. A natural interpretation of Aristotle's view is that perceiving that we see and hear is a special case of perception—as though, in addition to cases of normal perception such as seeing and hearing, we sometimes cognize that we are seeing and hearing; and Aristotle is making the claim that such cognition is also a kind of perception. I'll defend an alternative interpretation of Aristotle's claim. Perceiving that we see and hear is not a special case of perception but is rather a necessary condition for any ordinary perception whatsoever. In what follows, I'll rehearse two arguments supporting this alternative interpretation: first, that it makes better sense of the place of the argument of our passage, $425 \mathrm{~b} 12-25$, within the line of argument from De An. 2.12 to the end of 3.2; and second, that the interpretation resolves certain difficulties of interpreting the argument in 425b12-25.

If Aristotle's view was that perceiving that we see and hear is a special case of perception, then the first half of De An. 3.2 (425b12-26a26) would be nothing more than an aside without relation to the discussions that precede or follow it. On the other hand, taking Aristotle's view to be that perceiving that we see and hear is a necessary condition for perception fits this section within a continuous line of argument from 2.12 to the end of 3.2. The argument prior to 2.12 presents a partial account of perception as a continuous affection linking sense object with sense organ by means of a sense medium (metaxu: literally, a continuity). What the coloured object excites, for example, is neither the sensitive faculty nor the sense organ directly but is rather the medium of sight, the 
transparent. It is this, the continuous transparent, which, excited by the sense object, in turn excites the sense organ. So sight takes place through an affection of the sensitive faculty not by the coloured object itself but by a medium. And of course, it is not just the distal senses which require a medium: at 2.11, Aristotle argues that flesh is the medium, not the organ, of touch.

De An. 2.12 then raises the question, why does the media of perception not itself perceive? The media would perceive if being affected in a certain way were a sufficient condition for perception. For both the media and the sense organ are excited or affected in similar ways. The question, posed at $424 \mathrm{~b} 16-17$, is: "What then is smelling, besides a sort of suffering or being acted upon?" I take it that this question is not rhetorical. That is, Aristotle's claim is not that smelling is just a sort of suffering or being acting upon. Rather, the preceding discussion has shown that being affected in a certain way is a necessary but insufficient condition for perception. The question now at hand is: what else is required to provide a sufficient condition for perception?

At 425b12, Aristotle turns suddenly to the topic of perceiving that we see and hear. He doesn't explicitly state the claim that this higher-order perception is the additional component required for perception. The argument of 425b12-25 does not defend this thesis but addresses a question that subsequently arises: is such perception the office of a special faculty? So, unless he is simply abandoning his earlier question, he must believe that he has tacitly answered the earlier question. I take it then that Aristotle believes that his earlier question has been answered by turning to the topic of perceiving that we see and hear. If so, then this higher-order perception is not a special case of perception but rather is a necessary condition for any perception. 
Now, what is the activity which is perceiving that we see and hear? Kosman holds that perceiving that we see and hear is, in Aristotle, what he calls 'apperceptive awareness'. Kosman writes that "to perceive ... is not simply to be affected but to perceive that one is affected." Perception is thus "affection of which the living organism is conscious." One way of cashing out this suggestion is as follows. Perceiving that we see and hear is a turning of one's attention to the affection of the sense organs. What I mean by attention here is a prosaic and common phenomenon. We can, for example, attend to some item in our visual field while ignoring other items; when we suddenly notice what was previously unnoticed, it often comes as something of a surprise. Compare suddenly noticing background noise. Our sense organs are certainly affected by all items in our visual or aural fields. But if we do not attend to an item, we do not, properly speaking, perceive it - in some moderately robust but not uncommon sense of 'perceive'. ${ }^{6}$ Notice that conscious attention is a necessary condition for perception, in this moderately robust sense of perception. And, as we've seen, perceiving that we see and hear is for Aristotle a necessary condition for any perception whatsoever. Although this falls short of showing that conscious attention is Aristotle's intended notion when he speaks of perceiving that we see and hear, it does give us some reason to take this interpretation.

If perceiving that we see and hear is a kind of consciousness, then it resembles the contemporary view of consciousness as a higher-order perception. ${ }^{7}$ Under this view, phenomenally conscious experience requires the subject's awareness of a state; and such awareness consists in the subject representing that state itself. Aristotle's use of indirect discourse, the 'that'-clause, suggests that he views perceiving that we see and hear as an 
awareness of a representation of the subject's own state. The contemporary debate over consciousness concerns whether consciousness is an intrinsic feature of mental states or, as a higher order perception or thought, a relational feature. Victor Caston argues that Aristotle offers an account of consciousness which cuts down the middle of this apparent dichotomy and so preserves the intuitions supporting each view while avoiding the difficulties of both. ${ }^{8}$ Although a conscious state is, on Caston's reading, a higher order state, it is not a second token mental state directed at the first. Rather, it is directed at itself as well as at a perceptible quality. As a reflexive relation, a conscious state is a single act of conscious perception is a token of two types, one intrinsic and one relational.

Caston is right that we may gleam from Aristotle such a response to the contemporary debate. But there's a reason why such comparisons between Aristotle and contemporary views could mislead. (I don't claim that Caston is himself misled.) For there's no evidence that Aristotle is engaged in a debate over the nature of consciousness. His use of an embedded sentence within a 'perceives that' clause may not indicate a substantive thesis about the nature of consciousness; it may just be a way of referring to an unanalysed notion of consciousness or attention. Moreover, he never presents an account of consciousness as a rival to alternative accounts. His opponents are not intrinsic or relational theorists of consciousness. Aristotle's aim is rather to distinguish a mode of life, one special kind of motion, from the physiological changes found in the sense organs and media. His opponents are those who would offer an account of the soul without reference to the special characteristics of life. These opponents are of two kinds. There are those who see the mark of the soul as a kind of self-motion and so give an account of the soul in terms of what is originative of motion. And there are those who see the mark 
of the soul that it "knows or perceives what is" and, on the guiding maxim that it takes one to know one, give an account of the soul in terms of natural principles. These views are discussed at De An. 1.2-5. Aristotle's appeal, at De An. 2.1, to the notion of life as the mark of the ensouled is offered as a fresh starting point.

Here's two other points of difference between the contemporary debate and Aristotle's purpose. First, contemporary higher-order consciousness theories are typically advocated in the spirit of naturalism. If consciousness isn't a special kind of state, but just a representation of ordinary mental states, then the phenomenon of consciousness doesn't raise a special problem for naturalist accounts of mental states. Arguably, such philosophical projects are far from Aristotle's purposes. And secondly, Aristotle's view most closely resembles a recent new approach in the debate, self-representational theories of consciousness. Such theories hold that a mental state is conscious just in case it represents itself. These theories resemble higher-order theories, with the added twist that the first-order state and the higher-order state are identical. ${ }^{9}$ However, there are difficulties for self-representational theories. Is the notion of self-representation a coherent one? In what sense is representing oneself a kind of representation at all? The very notion of representation seems to involve a relation between two nonidentical relata. These difficulties arguably do not arise for Aristotle. His model of perceptual content is not one of representation but assimilation. Just as the most basic mode of life, the one which corresponds to the nutritive soul, involves the assimilation of food, so too in perception the perceiver becomes formally identical with his object.

After this aside comparing Aristotle's view of consciousness and the contemporary debate, I'll turn to the second of the two arguments I'll give supporting my 
interpretation. Taking Aristotle's claim that we perceive that we see and hear as an attention which is required for any perception also makes the arguments within $425 \mathrm{~b} 12$ 25 intelligible. Recall that the difficulty canvassed in (b.1) rests on the assumption that whatever faculty perceives a special sense must also perceive the object of that sense. On the interpretation that perceiving that we see and hear is a special case of perception, this assumption is implausible, as I argued above. However, if perceiving that we see and hear is a kind of awareness of, or turning of one's attention towards, the affection of the sense organ caused, through the medium, by the sense object, then the assumption is plausible. For such attention might plausibly be called both a perception of the seeing, say, and a perception of the object so seen.

Next, notice that the argument of (b.2) is now not only intelligible but compelling. Our problem in understanding this passage lay in the assumption that a distinct sense could not perceive a special sense such as sight without there being a need for a further perception of this second-order perception. This assumption generated an infinite regress. For a distinct sense to perceive sight, there must be a further sense to perceive the second-order perception with a third-order perception, and so on. If perceiving that we see and hear were a special case of perception, there would be no reason to hold the assumption. But the assumption is plausible when we realize that perceiving that we see and hear is a necessary condition for any perception. Then if perceiving sight were not the office of the faculty of sight itself, there would be a further need to posit a third-order perception of the second order perception.

Thomas Johansen has recently argued that we can make sense of the regress in section (b.2) while holding that perceiving that we see is a special case of perception, a 
reflexive self-consciousness, and so the argument of this section does not force us to hold that perceiving that we see is a necessary condition for ordinary visual perception, an account of consciousness. ${ }^{10}$ Johansen is right that a kind of regress can be generated while holding that perceiving that we see is a special case of perception. For we may see; we may perceive that we see as an act of self-reflexion; we may perceive that we perceive that we perceive that we see as a further act of perception; and so on. However, such a regress is not vicious. In a vicious regress, typically, an adequate explanation of each stage of the regress depends in some way on the subsequent stage. So, since the series is unending, no stage in the series has an adequate explanation. For example, Aristotle's argument for the existence of an unmoved mover in Physics 8 proceeds through a vicious regress. Suppose that each moving thing is moved by a distinct moving thing. The movement of any stage is adequately explained by the movement of the subsequent stage only if that movement is itself adequately explained. The series must be unending if there is to be any motion whatsoever, and so the existence of motion shows that there is an unmoved mover. Now consider the regress of perceiving perceptions. Take any stage of the regress: my perception that I see, for example, and suppose that this is a special case of perception and not required for my seeing. Furthermore, suppose that the subsequent stage of the regress, perceiving that I perceive that I see, is also a special case of perception and not required for my perception that I perceive that I see. My perception that I see, then, doesn't require an explanation in terms of the next stage in the regress, the perception that I perceive that I see. If perceiving that we see is a special case of perception, then the regress in (b.2) is not troubling and would not constitute an argument for the conclusion that it is by sight that one perceives that they see. And, as we've just 
seen, Aristotle is well aware of the nature of regress arguments. So Johansen's

observation that we can describe a series of higher-order perceptions, while holding that such perceptions are special cases of perception and not necessary conditions for any ordinary perception, fails to make sense of the argument of (b.2). ${ }^{11}$

The parts of the passage I labeled (a) and (c) are also clearer. First, recall that if Aristotle's claim were that perceiving that we see and hear is a special kind of perception, it would be entirely unclear why Aristotle would describe such cognition as a kind of perception at all: for the object of such awareness would not be a sensible object, an aistheton, but an activity, an aisthanesthai. The awkwardness of this terminology dissipates if we view perceiving that we see and hear as a necessary condition for perception. And not only is it now natural to call this kind of cognition "perception," but to do so does not commit us to the thesis that the objects of such perception are truth bearers. Recall, the problem here is that the expression, "perceive that (hoti) I see and hear," used at $425 \mathrm{~b} 12$, perhaps suggests that the objects of such perception are truth bearers. But if perceiving that we see and hear is simply a turning of one's attention to the affection of the sense organs, then no combination of propositional components is entailed by the activity. Moreover, Aristotle sometimes uses expressions which do not employ 'that'-clauses. At 425b15-16, for example, he calls this kind of cognition a perceiving of sight (he tes opseos aisthesis). Finally, recall that the problem canvassed at (c) rests on the assumption that perceiving that we see and hear requires that we perceive the relevant sense organ. If perceiving that we see and hear were a special case of perception, there would be no reason to hold this assumption. However, suppose instead that perceiving that we see and hear is a kind of turning of one's attention towards the 
affection of the sense organ by the relevant medium. Then such perception is, in some sense, a perception of the organ.

This concludes the argument that the interpretation of perceiving that we see and hear as a kind of attention provides a better reading of 425b12-25. Notice, for making sense of (b.1), we require an interpretation of perceiving that we see and hear as a kind of attention: holding the claim that perceiving that we see and hear is a necessary condition for perception, but also holding that such perceiving that we see and hear is not a kind of attention, together would not be enough to render the respective assumptions plausible. So here's the story so far. I've rehearsed an argument that viewing the perception that we see and hear as both a necessary condition of perception and as a kind of attention makes better sense of the argument of 425b12-25 and of the place of this passage within the line of argument from De An. 2.12 to the middle of 3.2 .

\section{II}

I turn to Aristotle's account of the active intellect in $D e A n .3 .5$. As I said in the introduction, I will be concerned in this section whether the role of the active intellect in intellection analogous to the role of perceiving that we see and hear in perception. The analogy suggests both that the activity of the active intellect is not a special case of intellection but rather a necessary condition for any intellection; and that this activity is a turning of one's attention to the intelligible objects possessed by the potential intellect. I find these theses attractive for the simplicity and elegance with which they account for 
what little textual data De An. 3.5 and 3.8 gives us. Moreover, they portray Aristotle as giving a reasonable, if sketchy, account of concept acquisition and employment. But they are controversial claims. So we need to go carefully through this material.

Aristotle introduces a distinction between the so-called potential intellect, by which the mind can become all things, and the so-called agent or active intellect, by which the mind can make all things, at De An. 3.5 (430a10-17).

But since, as in the whole of nature, to something which serves as matter for each kind (and this is potentially all the members of the kind) there corresponds something else which is the cause or agent because it makes them all, the two being related to one another as art to its material, of necessity these differences must be found also in the soul. And to the one intellect, which answers to this description because it becomes all things, corresponds the other because it makes all things, like a sort of definite quality such as light. For in a manner light, too, converts colours which are potential into actual colours.

There is a danger of misinterpretation here which is analogous with the misinterpretation I warned the reader against in the first section of this essay. There, recall, the misinterpretation was that of viewing one's perceiving that we see and hear as a special case of perception instead of a necessary condition for perception. Here, one might view the activity of the active intellect as a special case of intellection. The view might be spelt out as follows. When in the presence of a particular substance, our intellects may enter into formal identity with the intelligible form which makes that substance the sort of thing it is: it is in this sense, according to this view, that our minds can become all things - or rather, can become all intelligible forms. But, the view would continue, in 
addition to this cognitive ability, our intellects have the capacity to enter into formal identity with intelligible forms even in the absence of a particular substance instantiating that form: it is in this sense that our minds can make all things.

I will argue for a rival interpretation from the picture just sketched. The distinction of the intellect becoming all things and making all things is not describing two different activities both of which are thinking but is rather describing two different kinds of activities only one of which is actually thinking. In particular, I hold that Aristotle's discussion of the intellect becoming all things concerns a passage from the first potentiality to the first actuality of intellection; the discussion of the intellect making all things concerns the passage from the second potentiality to the second actuality of intellection. This will suggest that the relation holding between the active and the passive intellect is analogous to the relation holding between the perception that we perceive and the special senses. For, just as the perception that we perceive is not a special case of perception but is rather a necessary condition for any actual perception, so too the activity of the active intellect is not a special case of intellection but is rather a necessary condition for any actual thought.

Aristotle has a tripartite division of stages of actualization. One may have the potential to acquire a capacity; this is a first potentiality. One may, having actualized this potential, possess a capacity; this is a first actuality (also called a second potentiality ${ }^{12}$ ). One may exercise this capacity; this is a second actuality. Aristotle's favorite illustration of these distinctions is the acquisition, possession and exercise of knowledge. For example, a child is born with the first potentiality to learn a language; in passing from first potentiality to first actuality, the child, being instructed, acquires the linguistic skills 
required to be a competent speaker of that language; in passing from first actuality to second actuality, the competent speaker employs these skills — she speaks (or understands the speech of another).

The first passage, from first potentiality to first actuality, is a kind of alteration (alloiosis) and, in the case of the acquisition of knowledge, requires external causation in the form of instruction. More fully explicating this distinction among potentiality and actualities, with respect to perception, will require a brief excursus into Aristotle's discussion, in De An. 2.5, of the question, why there is no sensation of the senses themselves? That is, why do they produce no sensation (aisthesin) apart from external sensible objects? The answer is that the external stimulation of the sense organs is a necessary condition for perception or, more precisely, the passage from the first actuality of perception, the aisthetikon, to the second actuality of perception, aisthanesthai. The second passage, from first actuality to second actuality, is not an alteration and, in the case of the exercise of knowledge, does not require external stimulation. It is tempting to say that the passage from first actuality to second actuality, in the case of perception, also does not require external stimulation but this is a disanalogy with the case of knowledge. Although the passage from first actuality to second actuality does not generally require external stimulation, in the case of perception this is required. I take it that this is part of the argumentative purpose of 2.5: external stimulation of the sense organs is a necessary condition of perception despite it being a passage from first actuality to second actuality; otherwise, there would be sensation of the senses themselves.

With this set-up in the background, I'll now argue that the description of the intellect becoming all things in De An. 3.4 describes the passage from first potentiality to 
first actuality. Thus this, the actuality of the so-called potential intellect, is a necessary precondition for thinking but is also an insufficient condition for thinking. Then I will argue that the description of the intellect as making all things in De An. 3.5 describes the passage from first to second actuality.

De An. 3.4 (429a18-24) opens with a description of the first potentiality of intellect as a kind of pure capacity.

The mind ... since it thinks all things, must needs, in the words of Anaxagoras, be unmixed with any, if it is to rule, that is, to know. For by intruding its own form it hinders and obstructs that which is alien to it; hence it has no other nature than this, that it is a capacity. Thus, then, the part of the soul which we call intellect ... is nothing at all actually before it thinks. [Italics mine]

The notion of capacity employed here is capacity in the sense of first potentiality; and the notion of thinking here is the second potentiality or first actuality of the intellect. This is made clearer later in the chapter, at $429 \mathrm{~b} 5-9$, where explicit reference is made to Aristotle's example of second potentiality as the possession of knowledge.

[W]hen the intellect has thus become everything in the sense in which one who actually is a scholar is said to be so (which happens so soon as he can exercise his power of himself), even then it is still in one sense but a capacity: not, however, a capacity in the same sense as before it learned or discovered.

Clearly, Aristotle is describing, in his description of the intellect becoming everything, a passage from first potentiality to second potentiality. 
I turn to the passage from the second potentiality to the second actuality of intellect. Now, on the view that the activity of the intellect is a special case of intellection, the discussion of the active intellect in 3.5 is an aside without relation to what precedes it. Viewing the activity of the active intellect as a necessary condition for thinking, however, places the discussion in 3.5 within a continuous line of argument. I have noted that $\mathrm{De} A n .3 .4$ describes an intellect which becomes all things. The question arises, once the intellect has become all things, why does the intellect not always think all things? That is to say, the sense in which the intellect becomes all things describes a necessary but insufficient condition for thinking: if the account in 3.4 were describing a sufficient condition for thinking, then the intellect which becomes all things always would be thinking all things. There must be another component to thinking: this is the contribution made by the active intellect.

These considerations suggest that the activity of the active intellect is a necessary condition for the second actuality of intellection. ${ }^{13}$ What is this required activity of the active intellect? The analogy between perception and thought, which Aristotle often draws, is suggestive. Is the activity of the intellect a kind of attention or consciousness? ${ }^{14}$ On this picture, the thinker acquires the capacity to entertain a particular object of thought through the process of concept acquisition described in De An. 3.4. However, to possess object of thought in this manner is not to be continuously thinking. Just as we may have sensible forms in our visual field, which we do not perceive until we attend to them, so too we have intelligible forms in our intellects of which we do not always think. Actual thinking happens when the thinker turns his attention to one of the intelligible forms within his conceptual resources. 
In taking this line, I'm advocating what Michael Wedin calls a spring theory. According to spring theories, acquired thoughts are housed in the passive intellect as things possessed with a second potential status; they are brought to second actuality and then occur in episodes of thought by the autonomous activity of the active intellect. I'll next canvass a few alternatives to this interpretation. Some scholars have held that, although there must be another necessary component to thinking so to explain intermittent human thought, this component is not a contribution made by the active intellect. Rather, according to what Wedin dubs a surge theory, the active intellect is indeed always thinking all objects of thought. The fact that human thinkers sometimes think one thing and sometimes another is to be explained not by the activity of the active intellect but by external factors which block the human thinker's awareness of certain thoughts variously. According to surge theory, the active intellect is not offered as a response to the question why the intellect is not always thinking all things. As such, on surge theory the discussion in 3.5 again unattractively seems to be an aside unrelated to what preceeds it. Moreover, the view faces serious difficulties in explaining the sense in which intellection is a life activity and so a kind of autonomous self motion. So there are these reasons to favour my proposal over surge theories. ${ }^{15}$

Some other scholars have held that the active intellect is a distinct faculty from the passive intellect, and one capable of existence post mortem. One item of textual evidence apparently in favour of this interpretation is Aristotle's claim at De Anima 3.5 that the active intellect, unlike the passive intellect, is separate. Referring to the active intellect, he writes: 
And this intellect is separate, unaffected, and unmixed, being in essence activity. For that which acts is always superior to that which is affected, and the first principle to the matter. Actual knowledge is identical with its object; but potential knowledge is prior in time in the individual but not prior even in time in general; and it is not the case that it sometimes thinks and at other times not. In separation it is just what it is, and this alone is immortal and eternal. (430a17-23; my translation)

This passage has been controversial practically since it was written and I can only indicate here how an interpretation of separation terminology affects our interpretation of this passage. It is not clear even what it is from which the active intellect is separate. I hold that it is the body from which the active intellect is separate; on this interpretation, Aristotle is returning in this passage to a question he raised earlier. Aristotle begins the De Anima with a survey of aporia. He continues:

There is also the problem whether the attributes of the soul are all common also to that which has it or whether any are peculiar to the soul itself; for it is necessary to deal with this, though it is not easy. It appears that in most cases the soul is not affected nor does it act without the body, e.g. in being angry, being confident, wanting and perceiving in general; although thinking looks most like being peculiar to the soul. But if this too is a certain function of imagination or of a faculty which does not perform its function without the imagination, then it would not be possible even for this to perform its function without the the body. If then there is any of the functions or affections of the soul which is peculiar to it, it will 
be possible for it to be separated from the body. But if there is nothing peculiar to it, it will not be separable. (403a3-12; my translation, based on Hamlyn)

Aristotle lays down here a condition for separability. Notice that he does not claim that inseparability from the body amounts to being always found with some body. Rather, what is both necessary and sufficient for the soul to be separable from the body is its having a peculiar function: that is to say, the separability of the soul or some part of the soul hinges on its having a distinctive characteristic activity. In the statement of the aporia, Aristotle mentions several activities that necessarily involve physiological changes. Although there are unstated reasons to believe that the intellect does not require such changes, Aristotle worries that the intellect is nonetheless inseparable from the body, since it does not perform its function without the imagination. Aristotle seems to hold that the intellect always employs representations, the ability to represent is the office of the imagination, and the imagination acquires the ability to entertain a given representation through perception. ${ }^{16}$

There is a standard interpretation of separation terminology in Aristotle as referring to a capacity for independent existence. Under this interpretation, the claim that the active intellect is separate from the body is the claim that the active intellect, as opposed to the passive intellect, is capable of existing independently from the body. This interpretation could lend support to the view that the active intellect will survive death; alternatively, as I'll discuss in more detail below, the interpretation could lend support to those who hold that, where the passive intellect is a human intellect, the active intellect is the divine intellect. ${ }^{17}$ However, those who hold these views of the active intellect are hard 
pressed to explain why the separation of the active intellect follows from its activity, where the inseparability of the passive intellect follows from its passivity.

The notion of ontological independence isn't obviously equivalent to the notion of having a capacity for separate existence. A thing may have the ontological status of a being independently of standing in a tie to something else, without it being the case that the first thing can exist without the second. Consider propria, necessary but inessential properties. Although these properties are necessary, a substance is not a being in virtue of standing in some tie to its propria. So although, for example, Callias cannot exist without a proprium for humans — say, risibility—Callias's claim to having the ontological status of a being does not depend on his being risible. For this reason and others, there has been a growing recognition in the secondary literature of the inadequacy of the view that certain separation terminology in Aristotle refers to a capacity for independent existence; and I've argued at length myself that the notion of ontological independence in Aristotle does not concern a capacity for independent existence. ${ }^{18}$ I won't rehearse this argument here; rather, I'll merely spell out its consequences for our interpretation of the active intellect.

I hold that separation terminology, when it refers to a notion of ontological independence, does not refer to a capacity for independent existence but merely to the admission of the ontological status of a being independently of that being standing in a tie to anything else. Under this interpretation of separation terminology, the claim that the active intellect is separable from the body is not the claim that the active intellect can exist apart from the body but is instead the claim that it does not depend on the body for its status as a distinct kind of thing. Since Aristotle individuates natural kinds by their 
characteristic activities, this is to say that the active intellect does not depend on a body for its distinctive function. Here's one way of cashing out this independence. For its passage from a first potentiality to a second, the intellect depends on the bodily sense organs so to receive the perceptual information which leads to concept acquisition. For its passage from the first actuality to the second actuality, however, the intellect does not depend on the bodily sense organs. Although concept acquisition requires a body, the further actualization of a concept, the characteristic activity of the intellect, requires only attention. Such an interpretation offers several attractions. It would explain why the separation of the active intellect follows from its activity, where the inseparability of the passive intellect follows from its passivity. And it would explain how Aristotle resolves the relevant aporia. Recall, the aporia canvassed at $403 a 3-12$ is that there is evidence both for holding that the intellect is separate from the body and for denying it. Aristotle often resolves aporia by introducing a new distinction. My suggestion is that it is the distinction between the passive and active intellects which resolves this aporia. There is a process of concept acquisition, by which the intellect acquires a repository of forms retained as imaginative representations, and attention, by which the intellect, in attending to one of the forms among its conceptual resources, thereby engages in the activity of thought. So there is a sense in which the intellect depends upon the body and a sense in which it does not. $^{19}$

Let me briefly discuss a rival interpretation of separation terminology in the $D e$ Anima. Caston holds that it is not the body but other life faculties which is that from which the active intellect, and that the claim that the active intellect is separate is the claim that it is instantiated independently from other souls: although humans have both a 
sensitive and a rational soul, the divine intellect has only a rational soul. ${ }^{20}$ So that from which the intellect is separate are the nutritive and sensitive souls. Of course, the nutritive soul is also separate in this sense: plants have nutritive souls while lacking sensitive and rational souls. I hold that the active intellect is separate in both senses: it is independent from the body in virtue of having a non-physiological function; and it is instantiated apart from the other life faculties. Which of these two claims is being made at 430a17 is perhaps unclear. However, the fact that the active intellect is instantiated by the divine intellect without the other life faculties, makes good sense of his characterization, at $430 \mathrm{a} 23$, of the active intellect as, alone among kinds of soul, eternal. I find it attractive to hold that Aristotle here is claiming merely that one instance of active intellect, the divine intellect, is eternal. He is, at least, not obviously claiming that every intellect is capable of post mortem existence.

On this kind of view, the active intellect is instantiated as both a human intellect and a divine intellect. According to a now less common interpretation, the passive intellect is the distinctly human intellect possessed by all humans and the active intellect is the distinctively divine intellect possessed uniquely by the thought thinking thought of the unmoved mover. The identification of the active intellect with God was advocated by Alexander of Aphrodisias. Caston has recently offered a vigorous defence of a position similar to Alexander's. ${ }^{21}$ Caston opposes the view that the active and passive intellect are two capacities of one human faculty and identifies the active intellect with God.

However, as Caston notes, the

tradition of commentary has been unified in taking the second intellect to be a part of the causal mechanisms of thought: that is, it has generally been assumed that in 
the production of thought, there is some transition which is brought about by the second intellect, whether extrinsically or as a part of the human mind. ${ }^{22}$

Those who hold that the active intellect is a divine or superhuman intellect usually view the activity of this intellect as a component of ordinary human thought. Caston rejects this feature of interpretation. In his view, the active intellect is the distinct intellect of God. The human passive intellect and the active intellect operate independently, and the active intellect is not directly a part of human intellection. As Caston puts it, "the second intellect does not belong to human psychology at all, but rather theology." ${ }^{, 23}$ As such the passage discussing the active intellect is an excursus from the aims of the De Anima, and God makes a mere cameo appearance in the work.

I find Caston entirely persuasive that, if the active intellect is the divine intellect, then it is not involved in human cognition. One might view Caston's argument as laying down a challenge for those who hold that the active intellect is part of the human soul: to identify the gap in human rational cognitive functions for which an active intellect is needed over and above the passive intellect. The conjecture of this paper, that the activity of the active intellect is an awareness necessary for any intellection, is an attempt to meet this challenge. If this conjecture is correct, and Caston is correct that the active intellect plays a role in human cognition only if it is not the divine intellect, then of course it follows that the active intellect is not the divine intellect. ${ }^{24}$

However, I do not deny that the divine intellect is an instance of active intellect. In Meta. 12.7 Aristotle identifies the divine intellect with an activity of selfcontemplation. Any activity of the intellect is incidentally of itself, since the mind enters into formal identity with its object. But the activity of the divine intellect is essentially of 
itself and, in Aristotle's memorable turn of phrase, it is a thinking on thinking. An interpretation of the divine intellect is controversial and this is not the place for a detailed discussion. But I will note that Aristotle's discussion in these passages does not refute my claim that the distinctive activity of the active intellect is attention. On the contrary, it strikes me as not implausible that attention is both necessary and sufficient for a pure self-contemplation.

I turn to a few objections to the interpretation of the active intellect as a kind of attention. I have argued that the activity of the intellect is analogous to perceiving that we see and hear. If this claim is true, then one might expect Aristotle to draw this analogy explicitly: the activity of the intellect is to intellection as perceiving that we see and hear is to perception. What seems, at first blush, to be the strongest evidence against this claim is that, given the opportunity to draw an analogy with the active intellect, Aristotle does not mention perceiving that we see and hear. On the contrary, the analogy drawn in $D e$ An. 3.5 (430a10-17) is between the activity of the intellect and light. What I will argue now is that when we understand the context and purpose of this passage, it will be clear that it does not provide evidence against the claim that the activity of the intellect is a kind of attention.

The difficulty of interpreting the analogy between the active intellect and light is understanding what is the second term of each pair: to what is it that light stands in relation and to what is it that the active intellect stands in relation, such that these two relations are analogous? And: why does perceiving that we see and hear not stand in this relation? Notice this disanalogy between perceiving that we see and hear and the active intellect. The activity of the intellect is a sufficient condition for the intelligible forms, 
once possessed by the passive intellect, to be actually thought. That is to say, it is a sufficient condition for the passage from the first actuality to the second actuality of intellection. Perceiving that we see and hear, however, is a necessary but insufficient condition for the sensible forms to be actually perceived: external stimulation of the sense organs is also required to effect the passage from the first actuality to the second actuality of perception. On the other hand, light is a necessary and sufficient condition for the visibility of colour. Light is described at 418a26-b17 as the presence of something fiery in the transparent air or water; this allows the air or water to mediate - and so be actually transparent—-between the colour, the horaton, and the sense-organ, the aisthetikon of sight. This, then, is the analogy being drawn in this passage: light is to colour becoming perceptible as the active intellect is to the intelligible forms, possessed by the potential intellect, becoming actually thought. The analogy with light is appropriate in this context. Although, I maintain, both perceiving that we see and hear and the activity of the intellect are kinds of attention, to draw an analogy with perceiving that we see and hear in this context would be misleading.

I turn finally to two objections raised by an anonymous review for this journal. First, one might object that the alleged role of the active intellect, attention on previously possessed concepts, cannot be necessary for any intellection, since the acquisition of concepts is an activity of the intellect but one in which the active intellect is not involved. Aristotle sketches an inductive process of concept acquisition at APo 2.19. In some animals, sensible forms grasped through perception may be retained in the memory. Through repetition comes experience and recognition of the universal. The interpretation of Aristotelian induction is controversial and this is not the place for a detailed 
interpretation; it will suffice to note that Aristotle's account of concept acquisition does not conflict with the interpretation of the activity of the active intellect in the De Anima as attention. For I hold that, although attention is necessary for any intellectual activity, concept acquisition is not an intellectual activity. That is to say, the acquisition of a given intelligible form is not the second actualization of an intellectual ability with respect to that form. Rather, it is the transition from a first potentiality or mere capacity to a first actuality or ability. This is not to say that concept acquisition is not an activity: indeed, it is several activities and involves the second actualization of a variety of cognitive abilities, including perception and memory. Concept acquisition may also involve intellectual activity: the realization of an ability to entertain certain intellectual forms may facilitate the acquisition of others. And concept acquisition may thereby require attention: the attention necessary for the exercise of perceptual, intellectual and other cognitive abilities. But the acquisition of a given intellectual form is not an activity which is the realization of an ability with respect to that very form. If this is correct, then the objection lapses.

One might object instead that the view put forward in this paper, that the distinct activity of the active intellect is attention, is inadequate to explain the varied roles of the intellect outside the De Anima. I'll discuss just one of these roles. In several passages Aristotle asserts that it is by the intellect that we grasp first principles. ${ }^{25}$ Aristotle claims that the apprehension of a first principle is not preceded by an inductive process by which one acquires first an intellectual ability, with respect to that first principle, through the exercise of such cognitive abilities as perception and memory. Nor is the apprehension of a first principle the result of a deductive process. Aristotle concludes that the grasp of 
first principles cannot be through scientific understanding, practical reasoning or philosophical wisdom, and so it is through the intellect. Although the apprehension of a first principle is not preceded by a process by which a mere capacity is, through a first actualization, brought to be an ability, it does not follow that the apprehension of first principles does not involve the realization of an ability: indeed, it suggests that the activity of grasping first principles is the realization of an innate ability and does not require other cognitive abilities such as our perception, our memory, our ability to follow a demonstration, and so on, to bring about that ability. Nor does Aristotle's discussion in these passages clearly refute my claim that the realization or second actualization of this innate ability, when one contemplates first principles, is by attention on the content of this innate ability. On the contrary, it strikes me as plausible that, in the presence of these innate abilities, attention on a given first principle is both necessary and sufficient for intuition of that principle.

Let me bring the paper to a close. I've advocated an interpretation of the active intellect as a kind of attention or consciousness. The interpretation has the following virtues. First, the interpretation makes good sense of the argument of De Anima 3.4-5. Second, Aristotle often views perception and thought as analogous and the interpretation maintains an analogy between perception and thought (provided the interpretation of perceiving that we see and hear canvassed in the first section is correct); And third, it suggests interesting interpretations of certain other related cognitive processes, such as intuition, or our grasp of first principles, and the divine intellect. ${ }^{26}$ 
${ }^{1}$ See L. A. Kosman, "Perceiving that we perceive: On the Soul III, 2." Philosophical Review. 1969, 499-519; C. Osborne, “Aristotle, De Anima 3.2: How do we perceive that we see and hear?" Classical Quarterly 1983, 33: 401-11; V. Caston, “Aristotle on Consciousness." Mind. 2002, 111: 751-815.

${ }^{2}$ All translations of De An. are from R. D. Hicks, Aristotle De Anima with Translation, Introduction and Notes. (London: Cambridge University Press, 1907, 1965 Reprint), except where noted.

${ }^{3}$ This is in apparent conflict with his claim elsewhere that all of the senses "are accompanied by a common power, in virtue whereof a person perceives that he sees or hears (for, assuredly, it is not by sight that one sees that he sees. . for there is one sensory function, and the controlling sense organ is one, though differing as a faculty of perception in relation to each genus, e.g., sound or colour)" (On Sleep, 455a $13 \mathrm{ff}$. emphasis added). In this passage, Aristotle aims to explain how it is that all of the senses go idle simultaneously when one falls asleep. The claim that higher-order perception is the function of a common sense faculty, rather than the function of any of the special sense faculties, is central to his explanation of this phenomenon. There's a difficulty of interpretation, then, in reconciling De An. 425b12-25 and On Sleep 455a13ff., which I will ignore. My concern in the body of the paper is with the question, what is the activity which constitutes higher-order perception, and not with the question, what faculty performs this activity?

${ }^{4}$ D. W. Hamlyn, Aristotle's De Anima Books II, III Translated with Introduction and Notes, p. 122. (Oxford: Clarendon Press 1968) 
${ }^{5}$ Kosman op. cit., 508.

${ }^{6}$ One might hold, contra Aristotle, that we can perceive an item unawares. The distinction I am drawing here between perceiving awares and perceiving unawares is similar (modulo the comments above on misreading Aristotle as advocating a contemporary notion of consciousness) to that drawn—for example, by N. Block, "On a confusion about the function of consciousness" Behavioral and Brain Sciences_1995 18: 227-47, and M. Tye, Ten Problems of Consciousness. (Boston: MIT Press. 1995)between perceptual consciousness with access-consciousness and perceptual consciousness without access-consciousness. Contemporary higher-order theorists of consciousness draw on similar examples of nonconscious perceptual states. See D. Armstrong, A Materialist Theory of the Mind. (New York: Routledge, 1968), for the case of absent-minded driving; and P. Carruthers Language, Thought and Consciousness. (Cambridge: Cambridge University Press, 1996) for the case of blindsight. Such cases might be thought to lend support to higher-order theorists of consciousness. Aristotle is committed to denying that, strictly speaking, one can perceive unawares. For a discussion of how Aristotle might have handled blindsight cases, see Caston op. cit.

${ }^{7}$ See, for example, D. Rosenthal "Thinking that One Thinks," in Martin Davies and Glyn W. Humphries (eds.), Consciousness, (Oxford: Blackwell, 1993), and P. Carruthers, Phenomenal Consciousness: a naturalistic theory. (Cambridge : Cambridge University Press, 2000).

${ }^{8}$ Caston op. cit. 
${ }^{9}$ See, for example, U. Kriegel, "Consciousness as Intransitive Self-Consciousness: Two Views and an Argument." Canadian Journal of Philosophy 2003, 33: 103-132. Kriegel holds a weakened self-representational view that while conscious states are not identical to the states that represent them, they nonetheless entertain constitutive, non-contingent relations to them.

${ }^{10}$ Thomas Johansen, "In Defense of Inner Sense: Aristotle on Perceiving that One Sees," Proceedings of the Boston Area Colloquium in Ancient Philosophy, Vol. 21, edd. John Cleary and Gary Gurtler (Boston: Brill, 2005), pp. 244-45. Johansen characterizes his aim as a defence of the ascription to Aristotle of an inner sense theory but his main concern is to argue that perceiving that we see cannot be a necessary condition of any ordinary perception but is instead a special kind of perception. So, although the label 'inner sense theory' is often used to identify a theory of consciousness, Johansen holds that perceiving that we see is not Aristotle's account of consciousness but is rather a special case of perception. Johansen's characterization of his opponents' view is also potentially misleading for similar reasons. Caston, for example, takes perceiving that we see to be a higher-order theory of consciousness, although he holds that the first-order state and the second-order state are one and the same token state. That is to say, the view which Caston ascribes to Aristotle is what is usually called an inner sense theory of consciousness. So it would be more in keeping with current terminology to say that Johansen denies, and not defends, the ascription to Aristotle of an inner sense theory.

${ }^{11}$ Kosman makes a similar point in his "Commentary on Johansen," Proceedings of the Boston Area Colloquium in Ancient Philosophy, Vol. 21, edd. John Cleary and Gary 
Gurtler (Boston: Brill, 2005), pp. 280-82. Johansen argues that perceiving that we see cannot be a necessary condition of any ordinary perception but is instead a special kind of perception on the grounds that first and second order perceptions are different in complexity. In the first-order perception, one sees color or what has color. In the secondorder perception, one perceives also that one is seeing color. Johansen holds that the difference here is not well characterized by claiming that first-order perceptions are nonpropositional while second-order perceptions have propositional content. For Aristotle, Johansen claims, can express the content of a first-order perception by a proposition, writing at 418a15, for example, 'that [there is] color'. Moreover, first-order perceptions can involve accidental or common sensibles and so have content describable only with propositions such as that expressed by 'this white thing is moving towards me'. Rather, first- and second-order perceptions are different in complexity in the sense that "the second order perception conveys not just the content of the first order perception but also the information that one is perceiving that content" (op. cit., p. 258). However, it is precisely the point of contention between Johansen and authors such as Kosman whether the first-order seeing in expressions like 'perceiving that one sees' is a conscious perception of color or what has color.

${ }^{12} 412$ a10 suggests calling this stage first actuality since it is the actualization of first potential; 417a21ff. suggests calling this stage second potentiality since second actuality is its actualization.

${ }^{13}$ Hicks' translation misleadingly contributes to the appearance of the distinction as being between two faculties. Hicks translates: "and to the one intellect (ho men toioutos nous), 
which answers to this description because it becomes all things, corresponds the other (ho de) because it makes all things." However, instead of taking toioutos as adjectively modifying nous, we might just as naturally take it as a substantive. Then the passage reads: "there is some aspect by which intellect becomes all things and another aspect by which (the one and the same) intellect makes all things." Since the Greek supports either reading, this passage fails to provide evidence against the claim that the active intellect is not a separate faculty. In his commentary on this passage, Hicks, op. cit., 500, notes the possibility of two readings and their significance for the interpretation of the distinction. However, Hicks analyses the possibilities, both philological and philosophical, somewhat differently than as I have in the body of the essay. Hicks takes toioutos to be predicative and standing for both "passive" with ho men and "active" with ho de. He here translates the passage as: "the one intellect is passive, like matter, in that it becomes all objects, the other intellect is active, like the efficient cause, in that it makes all objects." Hicks continues: "If toioutos were attribute and not predicate, estin must mean 'there exists' and the sense must be "passive intellect exists in so far as it becomes all objects, active intellect, in so far as it makes all objects.' Those who press this interpretation deny that $\mathrm{A}$ [ristotle] ever really taught the existence of two distinct intellects in the sense in which the art which constructs is distinct from the material which it works upon: they content that A[ristotle]'s one intellect is sometimes passive, sometimes active, as it is sometimes theoretikos, sometimes praktikos." I have offered a somewhat different reading of the Greek and a different claim about the unity of the intellect. In particular, I claim neither 
that the distinction is temporal nor that it is related to the distinction of theoretical and practical reasoning.

${ }^{14}$ I don't claim any originality for this thesis. For antecedents, see F. Brentano, “Nous Poietikos: Survey of earlier interpretations." p. 322. Originally published in Die Psychologie des Aristoteles. (Mainz: Franz Kirchheim, 1867). Translated in and quoted from Essays on Aristotle's De Anima. Edd. Nussbaum and Rorty. (Oxford: Clarendon Press, 1992), and L. A. Kosman. "What does the maker mind make?" p. 355 in Essays on Aristotle's De Anima. Edd. Nussbaum and Rorty. (Oxford: Clarendon Press, 1992). This paper's contribution is to defend this line of interpretation through several new considerations: consideration of the analogy Aristotle often draws between perception and thought; considerations of the local argument of De Anima surrounding relevant passages such as $425 \mathrm{~b} 12-25$; and considerations of issues within these passages.

${ }^{15}$ See his “Aristotle on the Mind's Self-Motion," Self-Motion: From Aristotle to Newton, edd. M. Gill and J. Lennox. (Princeton: Princeton University Press, 1994), pp. 81-116. For other considerations against surge theory, see Wedin, op. cit.

${ }^{16}$ For discussion, see V. Caston, "Why Aristotle Needs Imagination,” Phronesis 1996, 41: 20-55.

${ }^{17}$ For a recent advocation of this latter view, see V. Caston, “Aristotle's Two Intellects: A Modest Proposal" Phronesis 1999, 44: 199-227.

${ }^{18}$ See, for example, D. Morrison, "Separation in Aristotle's Metaphysics" Oxford Studies in Ancient Philosophy. 1985, 3: 125-58; L. Spellman, Substance and Separation in 
Aristotle. (Cambridge: Cambridge University Press. 1995); and my “Aristotle on Ontological Dependence" Phronesis 2008, 53: 65-92.

${ }^{19}$ An anonymous reviewer for this journal objects that the active intellect is indeed dependent on the body since it presupposes the possession of concepts by the passive intellect, and concept acquisition depends on the body. However, even if the possession of a body is a pre-condition for the activity of the human active intellect, and so arguably the human active intellect cannot exist without a body, it does not follow that the active intellect is dependent on the body in the relevant sense of dependence. In general, not all necessary conditions are causes or asymmetric dependency relata.

${ }^{20}$ Caston, op. cit.

${ }^{21}$ Caston, op. cit.

${ }^{22}$ Caston, op. cit. p. 201.

${ }^{23}$ Caston, op. cit. p. 202.

${ }^{24}$ This is not the place for a detailed discussion of Caston's careful and innovative interpretation. It will perhaps suffice for my present purposes to show that some of the textual considerations which Caston brings to bear on the issue do not immediately refute my position. First, Caston holds that the taxonomic character of the discussion at 430a1017 suggests that subsequent division of the rational soul into a passive and an active intellect is a division between two natural kinds of the soul and not two faculties or divisions within the human soul. The argument at 430a10-17, as Caston notes, rests on the premise that it is because natural kinds exhibit certain characteristics that rational 
souls do as well. However this premise suggests only that the intellect is a natural kind, and not that the active and passive intellects are themselves distinct natural kinds. So while I agree with Caston that the active and passive intellects are not two distinct faculties, I disagree that they are not divisions within the rational soul. Second, Caston notes that Aristotle characterizes the active intellect and the divine intellect similarly. Both the active and the divine intellects are described as separate (430a17 and 1073a4, respectively), impassible (430a18 and 1073a11), unmixed or without matter (430a18 and 1074a33-34), actuality (430a18 and 1072a25-26; 1072b27-28), the same as its object (430a20 and 1075a1-5), prior in time to a capacity (430a21 and 1072b25), uninterruptedly or eternally thinking (430a22 and 1075a10), and solely what it is or just its essence (430a22-23 and 1075a1-5). But the active and divine are also contrasted in ways that suggest they are distinct: for example, the active intellect is called "more honourable" (430a18) while the divine intellect is called "most honourable" (1074a26; 1072a35-b1; 1072b28); the active intellect is the necessary condition for all thought (430a25) while the divine intellect is the necessary condition for everything (1072b13-14; 1075b24-26). So, although Aristotle characterizes the active intellect in ways that draw a surely intentional comparison with the divine intellect, some of these characterizations are striking in their differences. At best, we can conclude that the active intellect is like the divine intellect.

${ }^{25}$ See for example APo. 2.19 (100b15) and EN 6.6 (1141a7-8).

${ }^{26}$ Thanks to Eric Brown, Victor Caston, Brad Inwood, Fred Feldman, Calvin Normore, Mark Rollins, Margaret Scharle, Byron Stoyles, Paul Studtmann and Martin Tweedale for 
discussion; the participants of my graduate seminar on the De Anima at the University of Alberta; and the auditors at papers delivered at the American Philosophical Association Pacific Division Meeting, the Canadian Philosophical Association Annual Congress, and the American Philological Association Annual Meeting. I gratefully acknowledge the support of the Social Sciences and Humanities Research Council of Canada Standard Research Grant \#410-2008-0431. 